\title{
Protocolo de actuación forense ante la sospecha de meningitis bacteriana y shock séptico fulminante.
}

\author{
Protocol for the forensic action with regard to the suspicion \\ of bacterial meningitis and fulminant septicemia.
}

\section{A. Fernández-Rodríguez ${ }^{1}$ y B. Morentin Campillo²}

\section{RESUMEN}

Una importante tarea de las instituciones médico-legales es la colaboración con las autoridades sanitarias en la prevención de riesgos para la salud pública. Uno de ellos es la infección meningocócica, que puede cursar rápidamente y con evolución fatal, causando muerte súbita. Neisseria meningitidis es la principal causa de meningitis bacteriana y septicemia en niños y adultos jóvenes. Su temprana detección es de extrema urgencia, ya que permite el adecuado tratamiento de los contactos. El rápido desarrollo de estas infecciones imposibilita en ocasiones el diagnóstico antemortem, resultando imprescindible el diagnóstico forense. Aunque los hallazgos postmortem suelen ser los del síndrome de Waterhouse-Friderichsen, estos, a veces, pueden pasar desapercibidos, o estar causados por otras bacterias. Todo ello hace necesario un diagnóstico microbiológico forense.

Este artículo presenta un protocolo forense de actuación ante la sospecha de meningitis bacteriana y shock séptico fulminante. La toma de muestras para microbiología debe ser aséptica e incluir sangre, suero, LCR, líquido pleural, tejidos en fresco y orina. Estas muestras pueden remitirse al Instituto Nacional de Toxicología y Ciencias Forenses, donde se realizarán análisis específicos, que incluyen un screening antigénico y un diagnóstico de confirmación mediante PCR a tiempo real que identifica meningococo y su serogrupo. Los resultados de estas técnicas son informados 3 horas tras el inicio del análisis. También se realiza el cultivo bacteriano y PCR adicionales para detectar otras bacterias difíciles de aislar postmortem. La colaboración entre las distintas instituciones médico-legales y entre estas y las autoridades sanitarias es esencial para el adecuado manejo de estas graves infecciones.

Palabras clave: Muerte súbita infecciosa, meningococo, PCR, diagnóstico forense.

\section{ABSTRACT}

One of the main duties of medical-legal institutions is to collaborate with authorities to recognise and prevent risks to public health. One such risk is meningoceal infection, wich can progress rapidly and fataly, causing sudden death. In such cases, it is urgent to identify "Neisseria meningitidis" urgently in order to assure the appropiate treatment of people who have come into contact. This agent is a leading cause of bacterial meningitis and septicemia in children and young adults. Due to the rapid development of such infections, ante-mortem cultures sometimes are not taken, making the forensic diagnosis essential. Although post-mortem findings are often typical of the Waterhouse-Friderichsen syndrome, they may sometimes be overlooked or caused by other organisms. For these reasons, a microbiological forensic diagnosis is crucial.

This article presents a forensic procedure to diagnose the etiology of fulminant bacterial meningitis or septic shock. The aseptic sampling should include blood, sera, LCR, pleural effusions, urine and fresh tissues. These samples can be submitted to the Instituto Nacional de Toxicología y Ciencias Forenses for their early analyses. Antigenic tests are performed as screening techniques, and real-time PCR assays are also done to detect meningococcus and identify its serogroup. The results of these analyses are reported in 3 hours. Bacterial cultures are also performed. Additional PCR may be performed to diagnose other fragile bacteria that are difficult to recover post-mortem. The collaboration within all legal institutions and between those and health authorities is essential to best deal with this issue.

Key words: Sudden death; meningococcal infection; meningitis; meningococcus, PCR; forensic microbiology.

Correspondencia: A. Fernández-Rodríguez. Servicio de Biología. Instituto Nacional de Toxicología y Ciencias Forenses. C/ Luis Cabrera no 928002 Madrid. Tel. 91-562-91-90. Fax 563-69-24. E.mail: a.fernandez@mju.es.

${ }^{1}$ Especialista en Microbiología Clínica. Doctora en Farmacia. Facultativo del Instituto Nacional de Toxicología y Ciencias Forenses. Servicio de Biología. Departamento de Madrid.

2 Médico Forense. Doctor en Medicina. Servicio de Patología Forense de Bizkaia. Instituto Vasco de Medicina Legal. 


\section{I.- INTRODUCCIÓN:}

Aunque el principal deber de la patología forense es auxiliar a la administración de justicia, no podemos olvidar las obligaciones que como médicos tenemos con los familiares del fallecido y con la comunidad a la que servimos. La investigación basada en autopsias ofrece información útil y fiable en estudios sobre prevención y epidemiología en diversas áreas de la medicina. Esta información sobre las causas de la muerte es esencial en el desarrollo de políticas de salud nacional e internacional para la prevención y control de las enfermedades. Por otro lado, mediante la autopsia se pueden identificar enfermedades hereditarias de las que la familia debería ser informada para el oportuno consejo genético (por ejemplo, determinadas miocardiopatías y síndromes arrítmicos primarios), y enfermedades infecto-contagiosas. Estas últimas exigen la rápida instauración de medidas preventivas en los contactos cercanos para evitar casos secundarios. Se trata de patologías de indudable interés sanitario que se consideran enfermedades de declaración obligatoria.

La meningitis bacteriana y el shock séptico primario son las enfermedades infecciosas que tienen mayor trascendencia en patología forense, ya que pueden manifestarse como muerte súbita e inesperada [ $\mathrm{I}]$. Otro posible interés médico-legal es la investigación pericial ante una denuncia por mala praxis, en el caso de que el fallecido haya sido atendido por sintomatología infecciosa en un centro asistencial previamente a la muerte. Además de su interés médico-legal y sanitario, son enfermedades que siempre provocan gran impacto social, e incluso amplia repercusión en los medios de comunicación; tal fue el caso de la epidemia de 1996 y 1997, que dio lugar a diferentes campañas de vacunación durante esos años, y supuso la introducción en el calendario vacunal infantil de la vacuna conjugada frente a meningococo $\mathrm{C}$.

La modernización de las ciencias forenses implica la incorporación de nuevas tecnologías diagnósticas; algunas de ellas previamente introducidas en la rutina de la medicina clínica, que habrá que adaptar y optimizar para su uso forense. En la última década, el desarrollo de la tecnología del ADN y el empleo generalizado de la PCR (reacción en cadena de la polimerasa) como herramienta básica en el laboratorio han supuesto una revolución en el mundo de la criminalística. De igual manera, la aplicación de estas técnicas a la microbiología puede aportar nuevas herramientas en la investigación forense. En este sentido, la puesta a punto de métodos estandarizados que permitan identificar a aquellos patógenos que provoquen infecciones responsables de la causa de muerte puede ser de gran utilidad en la práctica forense.

El propósito de este artículo es presentar un protocolo de actuación ante la sospecha de una muerte por meningitis bacteriana o shock séptico fulminante (figura I). Puesto que la detección de una infección meningocócica implica la necesidad de comunicarlo a las autoridades sanitarias para organizar el tratamiento de los contactos, el principal objetivo será confirmar o excluir la presencia de esta bacteria con la mayor rapidez posible. Este protocolo incluye pautas de intervención precisas y rápidas que permitan la respuesta coordinada inmediata de los distintos profesionales (médicos forenses, patólogos, microbiólogos y médicos de Sanidad) e instituciones implicadas (Institutos de Medicina Legal, Instituto Nacional de Toxicología y Ciencias Forenses (INTCF), Consejerías de Sanidad y centros asistenciales).

El INTCF ha asumido la realización de estos análisis microbiológicos en muestras forenses por diversas razones: I) en el contexto de muerte súbita infecciosa no suele existir un diagnóstico clínico ante-mortem ni cultivos ante-mortem; 2) estas muestras requieren un análisis especializado y, en ocasiones, diferente del de las muestras clínicas que se manejan en hospitales; 3) ante una posible denuncia por presunta mala praxis no parece conveniente desde el punto de vista médico-legal que sea el propio centro afectado el que realice el análisis microbiológico. El INTCF efectúa análisis microbiológicos espeć́ficos de forma eficaz y rápida, incluyendo entre otras, técnicas moleculares. 


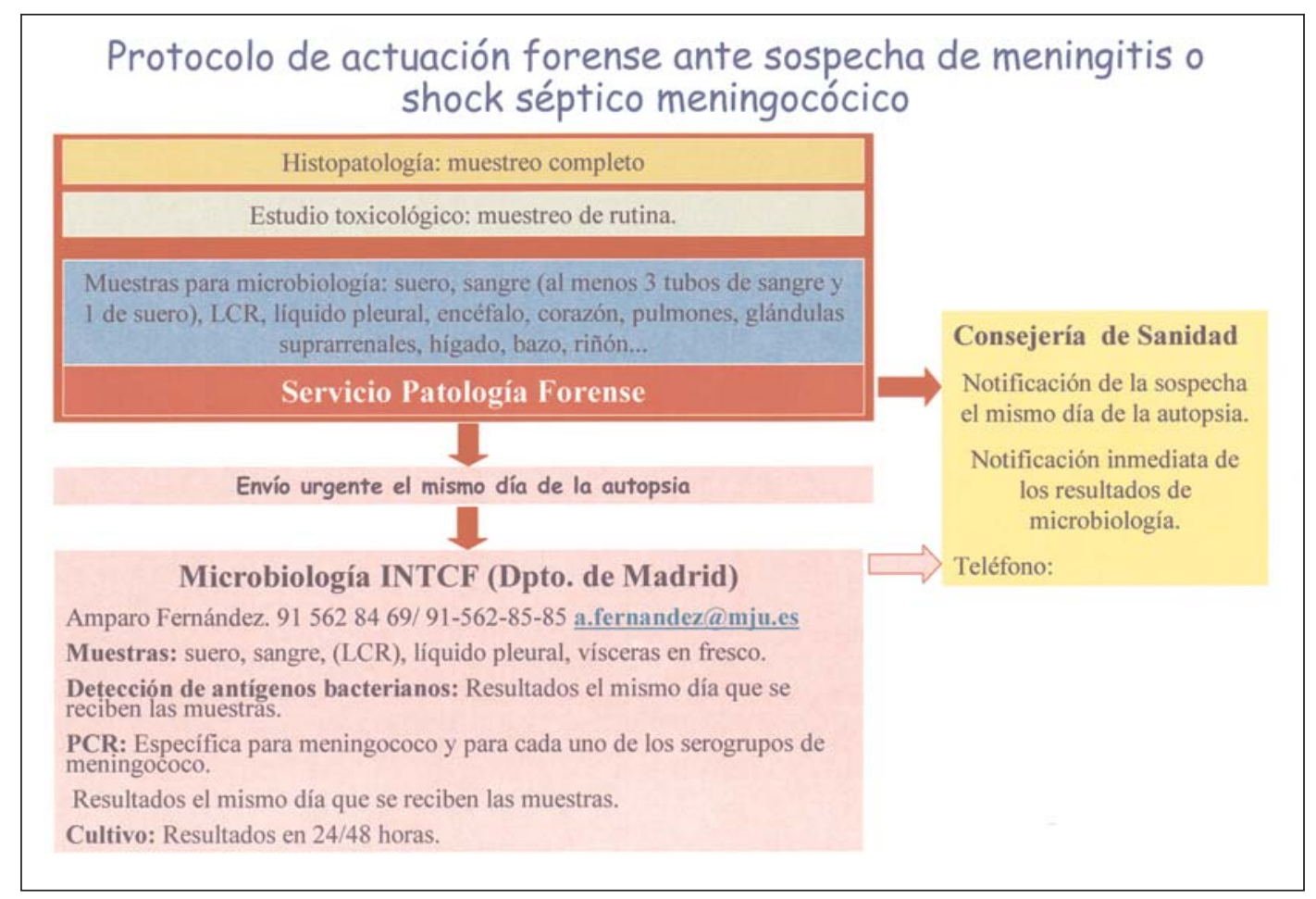

Figura $\mathrm{n}^{\circ}$ 1. Protocolo de actuación ante la sospecha de una muerte por meningitis bacteriana o shock séptico fulminante. Se indican las muestras que el forense debe tomar ante esta sospecha y los análisis que se van a realizar en el INTCF una vez que se formule esta petición. También se reseñan teléfonos y personas de contacto. La notificación de los casos a las Consejerías de Sanidad de cada comunidad autónoma se puede hacer indistintamente por el médico forense o por el INTCF una vez conocidos los resultados. Puesto que consideramos útil disponer de una copia del protocolo en la sala de autopsias, se ha dejado libre un espacio en el protocolo junto a la palabra "Consejería de Sanidad" para que cada centro incluya el teléfono de la que le corresponda.

\section{2.- ETIOLOGÍA Y EPIDEMIOLOGÍA:}

Los microorganismos más frecuentemente involucrados en la meningitis aguda bacteriana y/o shock séptico son Neisseria meningitidis (meningococo) y Streptococcus pneumoniae (neumococo) [2]. Clásicamente se ha defendido que el primero predomina en niños y adultos jóvenes y el segundo en adultos. No obstante, la introducción en el año 2000 de la vacuna conjugada frente a N. meningitidis serogrupo C en el calendario de vacunación infantil (así como las campañas de vacunación específicas efectuadas con esta vacuna), ha hecho que el patrón de presentación de esta enfermedad esté cambiando, observándose en los últimos años una disminución importante de la incidencia y las defunciones en niños [3]. La mayoría de las infecciones meningocócicas en España se deben a los serogrupos B y C [4], siendo mayor la tasa de mortalidad en pacientes con serogrupo $C$ que en aquéllos con serogrupo B [5]. Además, existen otras posibles bacterias causantes de meningitis, siendo las más frecuentes Haemophilus influenzae tipo b (que suele presentarse entre el período neonatal y los 6 años), Streptococcus agalactiae (estreptococo $\beta$-hemolítico del grupo B), que afecta al neonato, y Listeria monocytogenes.

Según los datos del Centro Nacional de Epidemiología, en el año 2003 la tasa de enfermedad meningocócica en España fue de 2,4 casos por 100.000 habitantes, con una letalidad del 8,8\%. Sin embargo, en la Comunidad Autónoma del País Vasco, la tasa fue sensiblemente más alta (5,2 casos por 100.000). En la mayoría de países europeos la incidencia presentó valores comprendidos en un rango de 0,5 y 3 casos por 100.000 habitantes [6]. 


\section{3.- CARACTERÍSTICAS CLÍNICAS DE LA INFECCIÓN:}

La meningitis bacteriana suele tener un comienzo rápido, con deterioro progresivo en el plazo de horas o escasos días. En ocasiones, en los días previos ha habido un síndrome febril, generalmente por infección de las vías respiratorias superiores. La tríada clínica clásica está compuesta por fiebre elevada, cefalea intensa y rigidez de nuca. Otros síntomas frecuentes son las náuseas y los vómitos. También suele haber alteraciones del nivel de conciencia (somnolencia, obnubilación, letargo, coma). En esta forma de presentación habitual, la meningitis suele ser diagnosticada en vida y los casos mortales suelen ocurrir en el ámbito hospitalario.

Ocasionalmente la evolución de la infección es atípica y especialmente agresiva; el paciente en muy pocas horas evoluciona hacia el coma, shock o muerte, antes de que los síntomas clínicos sean obvios y sin dar tiempo a un diagnóstico en vida. Un cuadro especialmente virulento es la sepsis meningocócica, cuya mortalidad es incluso mayor que la de la meningitis. Característicamente aparecen petequias cutáneas y el paciente evoluciona al shock en horas. Debido a esta presentación súbita, inesperada y atípica es requerida una autopsia médico-forense.

\section{4.- CARACTERÍSTICAS PATOLÓGICAS DE LA INFECCIÓN:}

Los cambios observados en el encéfalo de las personas que han fallecido por meningitis piógena o shock séptico van a depender del tiempo de evolución de la infección. En las formas fulminantes (con muy pocas horas de supervivencia) el diagnóstico macroscópico en encéfalo es muy difícil y la inflamación meníngea puede no ser aparente. Suele existir congestión meníngea y edema marcado. Microscópicamente se puede ver marginación de polimorfonucleares en las arteriolas de las leptomeninges. En estas formas fulminantes el shock séptico (síndrome de Waterhouse-Friderichsen) se manifiesta con hemorragia suprarrenal bilateral (figura 2), coagulación intravascular diseminada e hígado de shock. Puede haber afectación por la infección en el corazón (figura 3), pulmones o bazo (esplenitis). La muerte puede ser tan precoz que se produzca antes de que la meningitis se desarrolle.

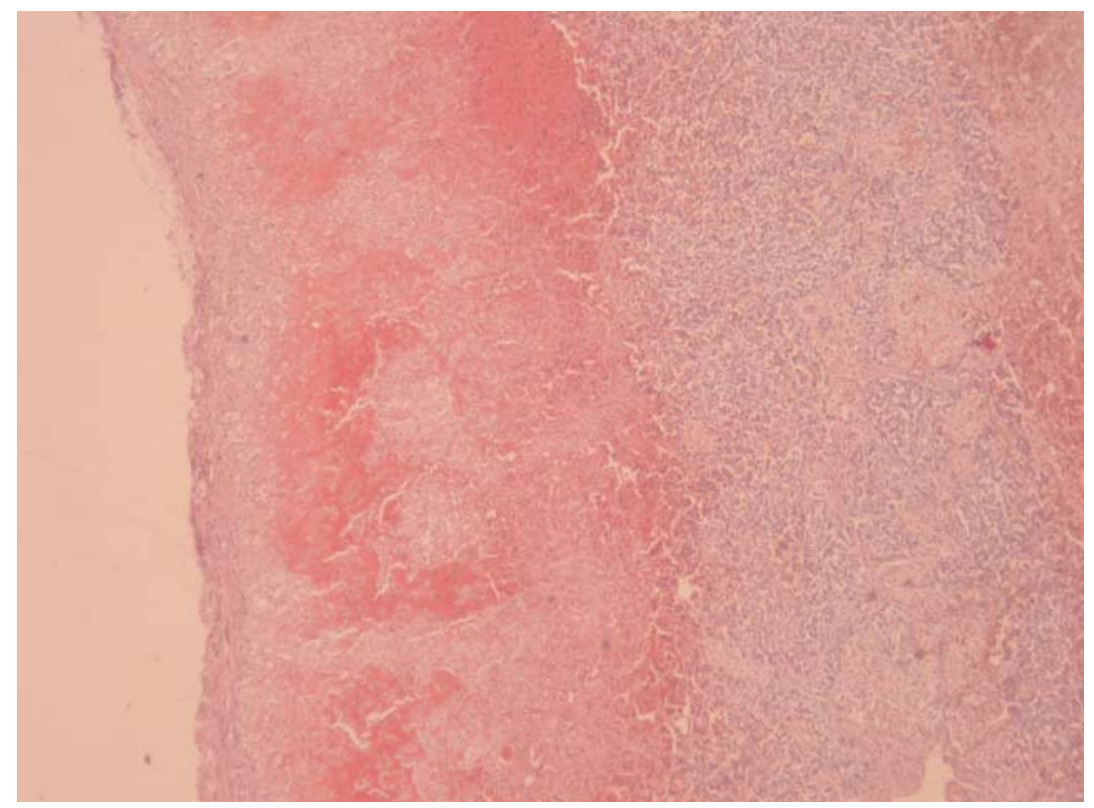

Figura $n^{\circ} 2$. Necrosis hemorrágica de la corteza suprarrenal debida a meningococemia (microfotografía, hematoxilina \& eosina). 


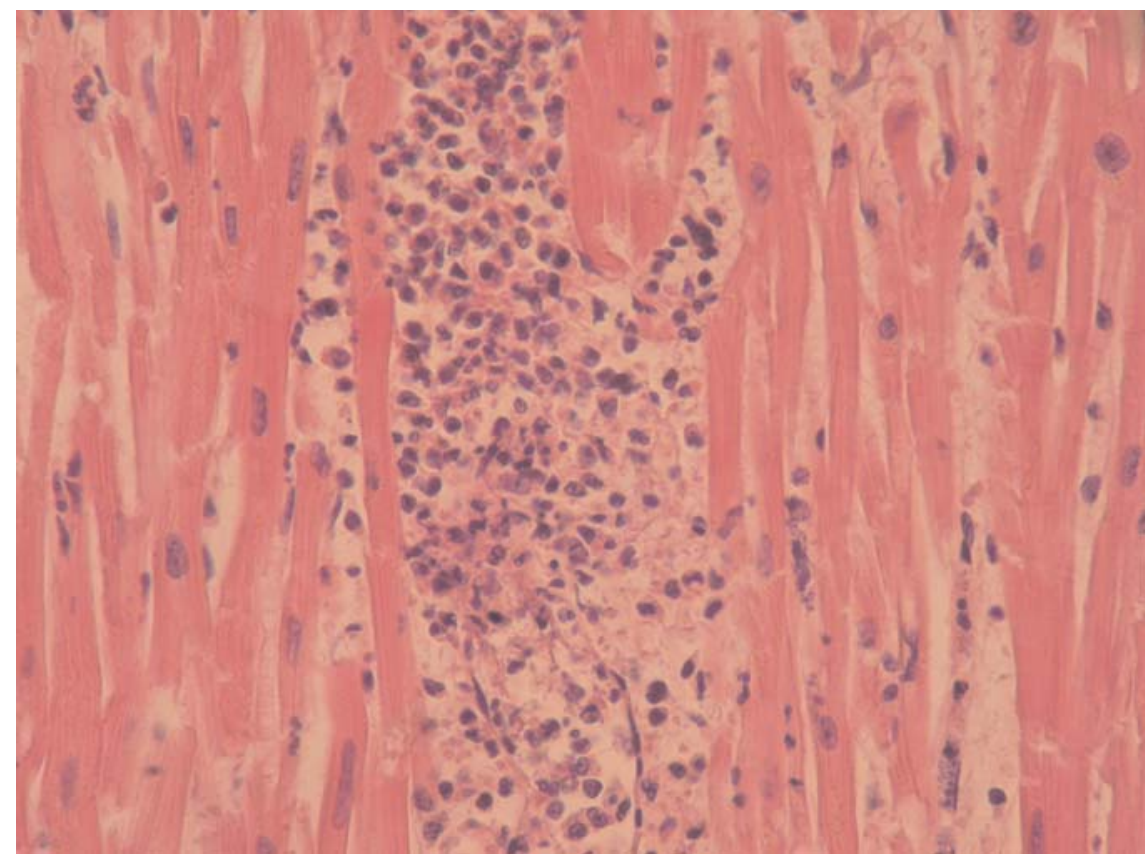

Figura $\mathrm{n}^{\circ}$ 3a. Sección de miocardio que muestra infiltrado inflamatorio de polimorfonucleares, de distribución preferentemente intersticial (microfotografía, hematoxilina \& eosina).

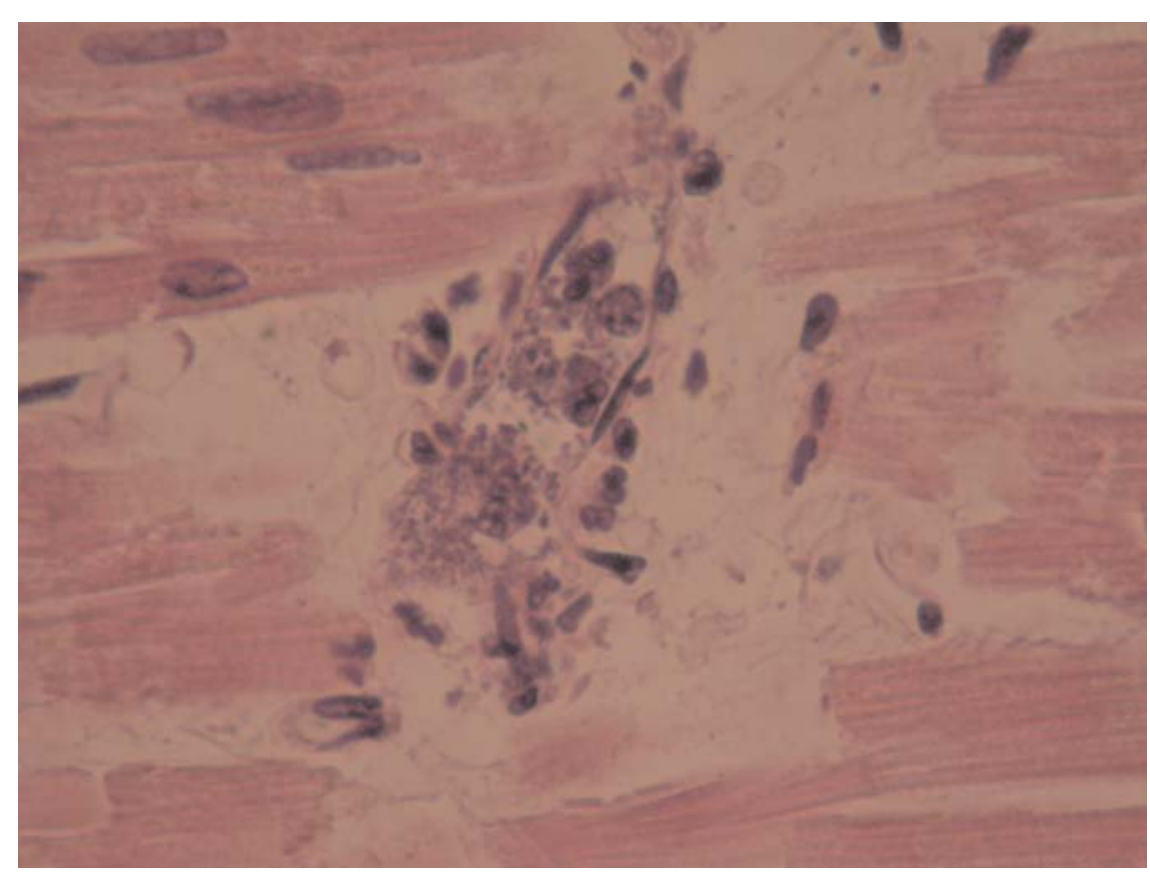

Figura $\mathbf{n}^{\circ} \mathbf{3 b}$. A mayor aumento, se aprecian imágenes sugestivas de colonias bacterianas de cocos con polimorfonucleares en el interior de un capilar del miocardio (microfotografía, hematoxilina \& eosina). 
En las formas agudas con más de 24-48 horas de supervivencia el exudado purulento meníngeo suele ser visible macroscópicamente (figura 4), si bien a veces la inflamación meníngea puede ser mucho más sutil (figura 5), e incluso no ser aparente en la inspección visual. Por

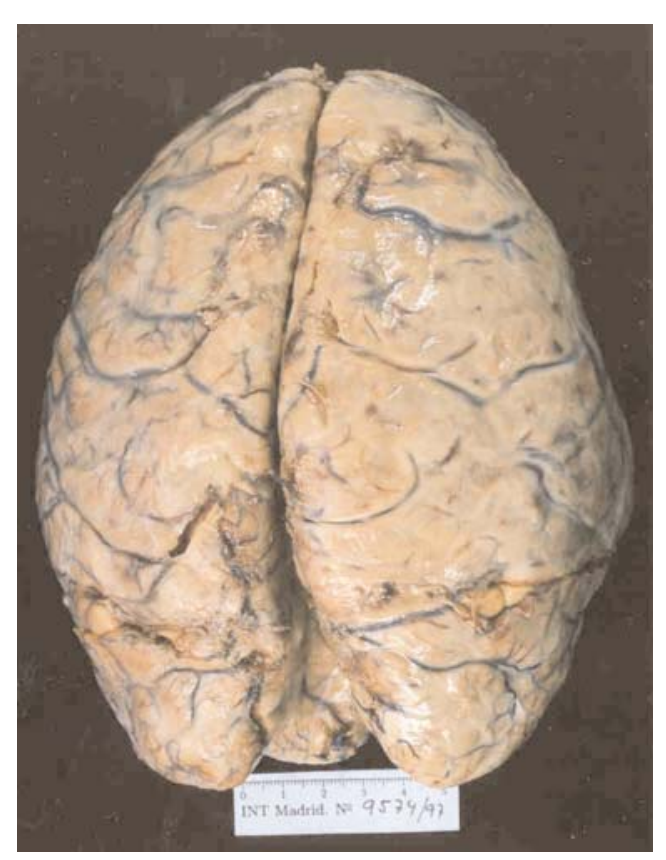

Figura $n^{\circ}$ 4. Vista externa del cerebro, en el que se observa evidente exudado purulento meníngeo. ello, se recomienda siempre el estudio histopatológico. Microscópicamente destaca el exudado inflamatorio agudo con presencia de polimorfonucleares en el espacio subaracnoideo (figura 6). En los casos menos severos la inflamación se localiza principalmente alrededor de los vasos sanguíneos. El edema cerebral puede ser tan intenso que, por aumento de la presión intracraneal, produzca herniación cerebral y hemorragia de Duret secundaria a enclavamiento. Además, la inflamación se puede extender hasta los ventrículos (ventriculitis purulenta) y hacia el parénquima cerebral (cerebritis focal).

\section{I.- ¿CUÁNDO DEBE EL FORENSE SOSPE- CHAR UNA SEPSIS MENINGOCÓCICA?}

Frente a cualquier muerte fulminante con presencia de cuadro febril (aunque sea de horas de evolución), presencia de petequias cutáneas y hemorragia suprarrenal, el forense debe informar de inmediato a las autoridades sanitarias de la sospecha de una sepsis meningocócica y actuar como recomienda este trabajo (figura I). Una vez se conozcan los resultados del análisis microbiológico, se volverá a llamar a las autoridades sanitarias competentes para informar de un resultado positivo o negativo, con objeto de que aquéllas tomen las decisiones más adecuadas para el tratamiento de los contactos.

De acuerdo a la experiencia de los autores, es este cuadro de sepsis meningocócica, y no el de meningitis, el más frecuentemente observado en los casos forenses.

\section{2.- RECOMENDACIONES EN EL ESTUDIO HISTOPATOLÓGICO}

Se recomienda un estudio histopatológico de todos los órganos. Con el fin de caracterizar lo más precozmente la naturaleza del posible exudado inflamatorio de la meninge se puede realizar con una torunda (y en acondiciones de asepsia) un frotis del mismo para estudio citológico (figura 7), cuyos resultados pueden ser casi inmediatos en el mismo Servicio de Patología. También se puede hacer en el momento una tinción de Gram con muestra de LCR. No obstante, sea cual sea el resultado de estos análisis, este no exime del posterior análisis microbiológico. Se recomienda fijar el encéfalo completo para su estudio neuropatológico, si bien previamente se pueden coger 2 ó 3 pequeñas secciones (de unos $2 \times 2 \mathrm{~cm}$ ) de la parte superficial del cerebro (incluyendo meninges) para su rápida fijación ( 24 horas) y posterior procesamiento y tinción de H/E lo más precoz posible (resultados en 48-72 horas tras la autopsia si son procesados en el Instituto de Medicina Legal). 


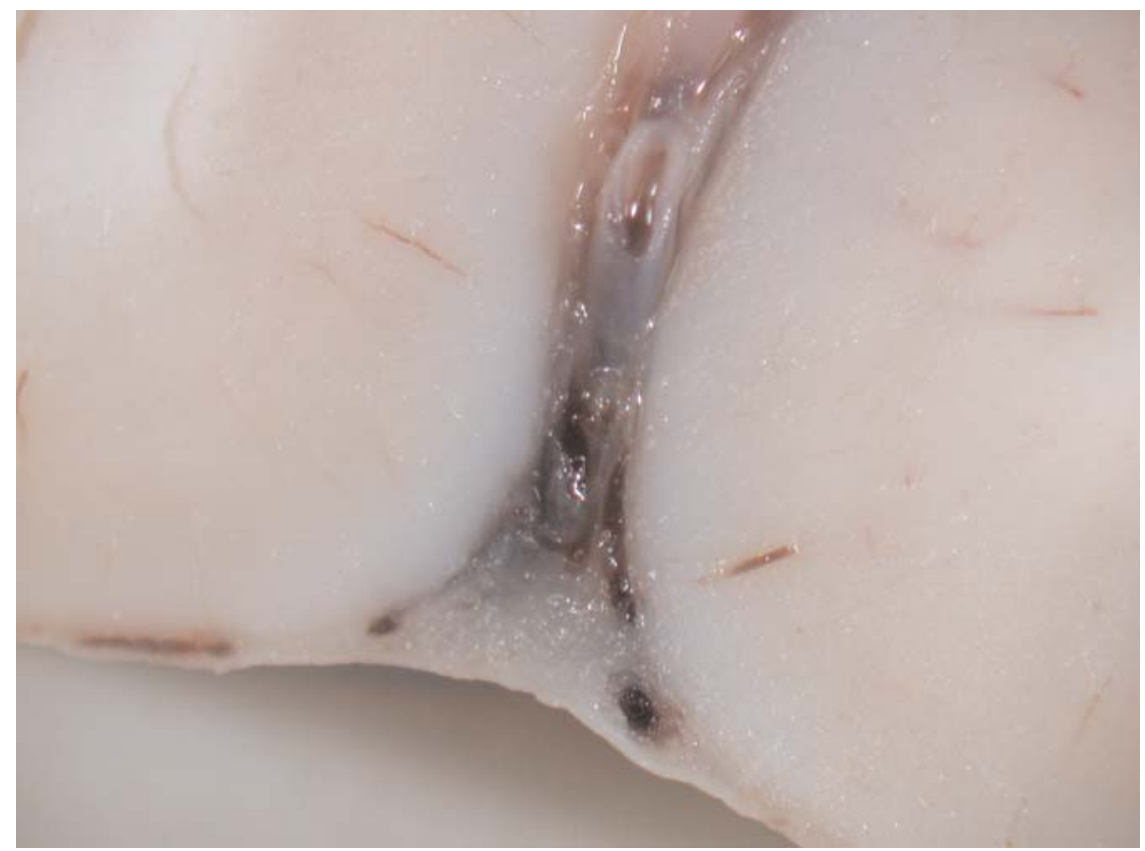

Figura $n^{\circ}$ 5. Sección coronal de la corteza cerebral que muestra una fina banda de exudado inflamatorio blanquecino en espacio subaracnoideo penetrando en el interior del surco cerebral, que podría incluso pasar desapercibido en un examen no minucioso.

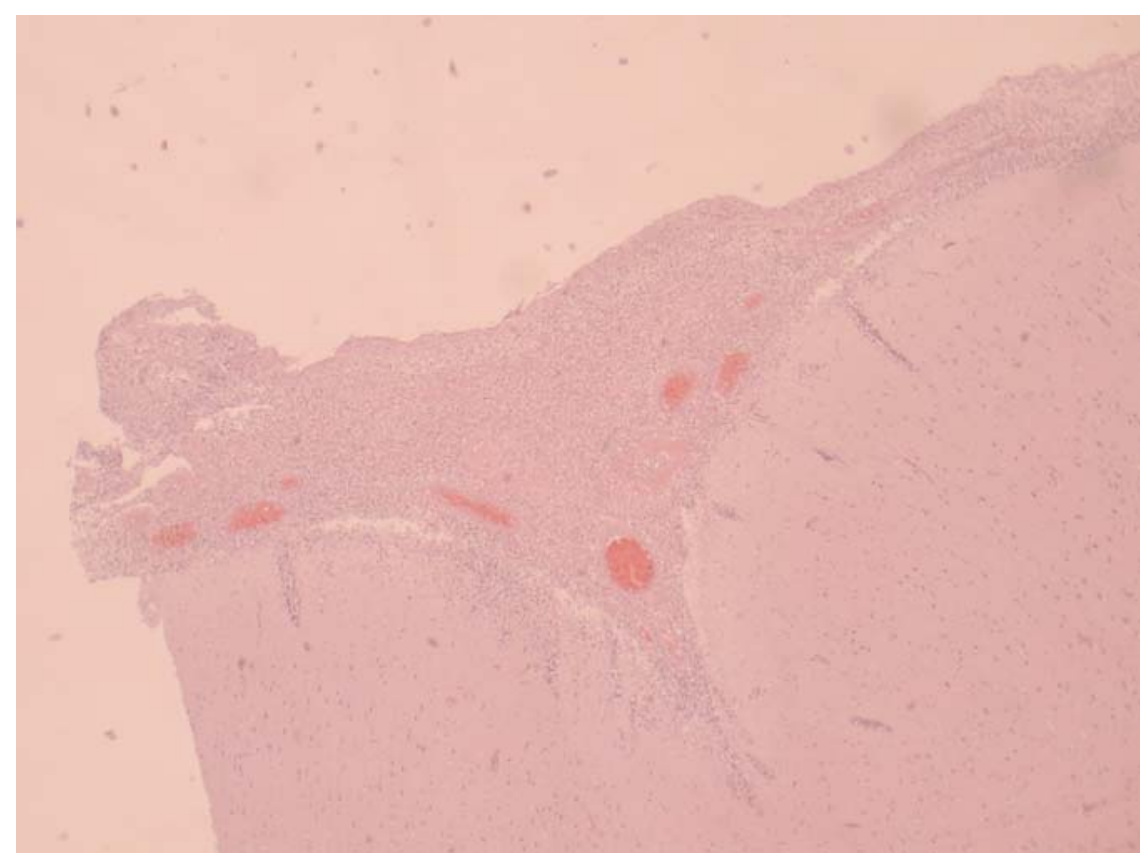

Figura $\mathbf{n}^{\circ}$ 6. Imagen microscópica del caso anterior. Exudado inflamatorio agudo compuesto casi por completo de neutrófilos localizado en el espacio subaracnoideo entre la aracnoides y el parénquima cerebral (microfotografía, hematoxilina \& eosina). 


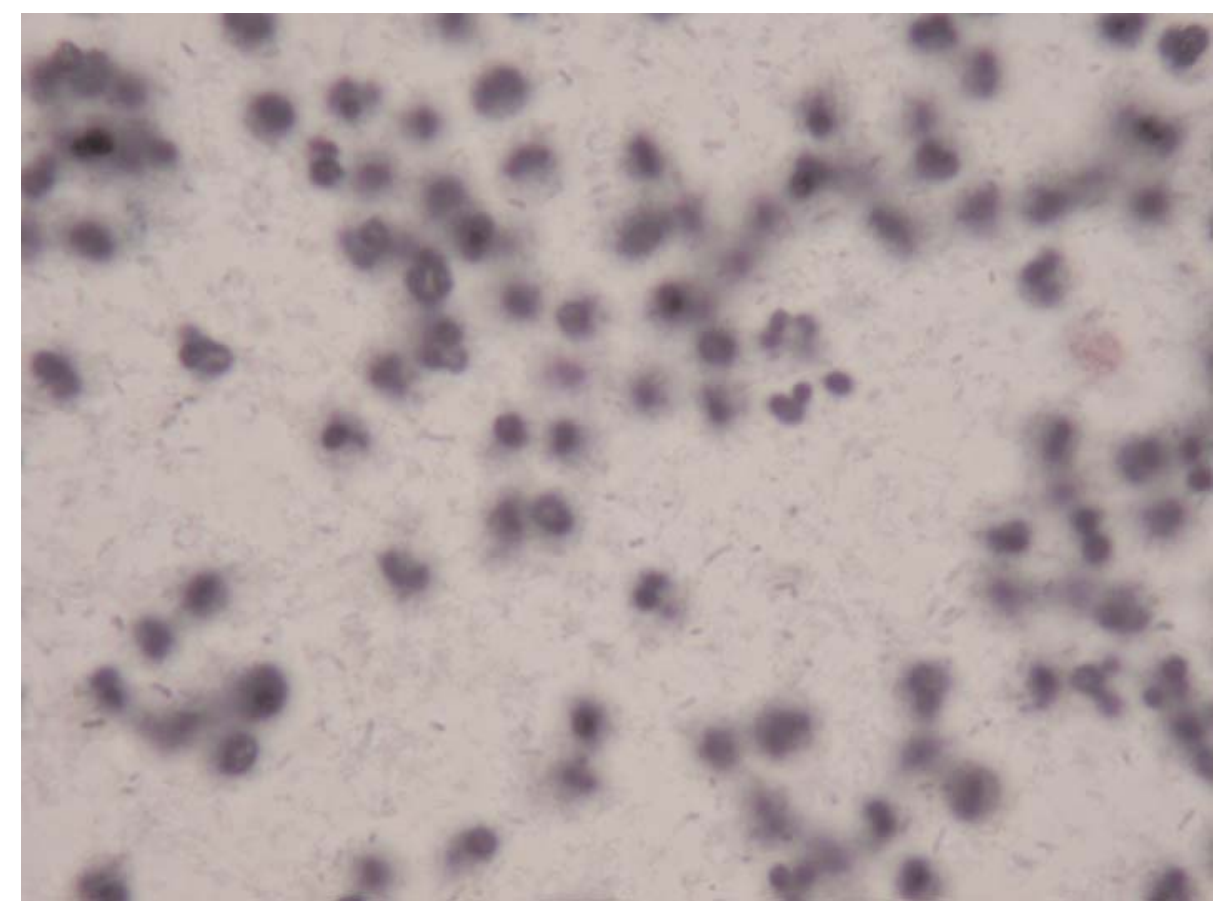

Figura ${ }^{\circ}$ 7. Citología de una extensión del exudado meníngeo que muestra múltiples neutrófilos. Así mismo, se pueden identificar a gran aumento microorganismos en forma de bastoncillo (bacilos) (microfotografía 100x con aceite de inmersión, hematoxilina \& eosina). El estudio microbiológico permitió la detección de Escherichia coli, como causante de una meningitis post-traumática e infección diseminada en una paciente de avanzada edad.

\section{5.- MICROBIOLOGÍA:}

5. I .- ¿CUÁNDO HAY QUE REALIZAR UN ESTUDIO MICROBIOLÓGICO?

En las autopsias con sospecha clínica o morfológica de meningitis o infección fulminante primaria sin origen conocido se debería siempre solicitar un estudio microbiológico.

Las razones para ello son varias:

1) Varios microorganismos pueden causar el mismo cuadro clínico y los mismos hallazgos histopatológicos [7];

2) el exudado purulento puede no ser detectado durante el examen macroscópico de autopsia, e incluso en las formas fulminantes, tal y como se ha comentado, el exudado inflamatorio agudo puede no ser evidente en el estudio microscópico;

3) Por las repercusiones en la salud pública es esencial determinar la identidad del organismo responsable y en el caso de la meningitis meningocócica también del serogrupo. Este diagnóstico va a determinar la quimioprofilaxis y la posible vacunación (no existe vacuna frente al serogrupo B) de los contactos expuestos.

\section{2.- PROTOCOLO DE ESTUDIO: MUESTRAS NECESARIAS Y ENVÍO.}

Las principales muestras necesarias para enviar al laboratorio son: sangre, suero, LCR, orina y vísceras en fresco (Figura I). Además, si existe efusión pleural o cualquier otro exudado, es conveniente analizarlo. Como regla general, en microbiología forense, se considera conveniente la 
detección del mismo microorganismo en más de un tejido o fluido corporal. Por este motivo se aconseja disponer siempre del mayor número posible de muestras. Todas las muestras deben tomarse en recipientes estériles y su envío debe ser inmediato desde la toma. Las muestras para estudios antigénicos y moleculares deben refrigerarse, mientras que se recomienda mantener a temperatura ambiente en vez de en refrigeración las muestras destinadas a cultivo.

\subsection{I.- SANGRE Y SUERO.}

De acuerdo a las recomendaciones publicadas en la literatura especializada, la sangre se debe tomar por punción intracardiaca transcutánea a tórax cerrado y tras la desinfección de la piel, o mediante punción directa del ventrículo derecho a tórax abierto. En este último caso, se debe aplicar una espátula al rojo sobre el miocardio. También es posible extraer la sangre, en idénticas condiciones de asepsia, de aorta o vena cava inferior. Sin embargo, según la experiencia de los autores también se consiguen resultados válidos con muestras recogidas mediante punción directa de una vía periférica (vena axilar o femoral), previa exposición de la misma en las mejores condiciones posibles de asepsia.

Se recomienda tomar, al menos, 4 tubos de sangre de 3 ó 5 ml: tres de ellos se van a destinar al estudio microbiológico:

- Un tubo se destinará al cultivo bacteriológico; se recomienda que este lleve polianetol sulfonato sódico (SPS) como anticoagulante, o citrato trisódico (TCS). No se recomienda que este tubo lleve fluoruro sódico como conservante o EDTA como anticoagulante, ya que ambos son tóxicos para muchos microorganismos.

- Un tubo se destinará a técnicas moleculares, que deberá contener EDTA sódico como anticoagulante.

- Un tubo con activador del coágulo se destinará a la recogida de suero; este tubo permite que, tras la centrifugación, el suero se separe directamente antes de llegar al laboratorio.

- El cuarto tubo, que se reservará para los análisis químicos-toxicológicos, deberá contener oxalato potásico como anticoagulante y fluoruro sódico como conservante.

\subsection{2.- LCR.}

Siempre que exista sospecha de meningitis es conveniente la extracción de LCR, que se hará mediante punción en la cisterna magna (entre los hemisferios cerebelosos) con aguja larga desde la parte posterior del cuello. Se coloca al cuerpo en decúbito prono y se inserta la aguja en la línea media bajo la base del hueso occipital y dirigida levemente hacia arriba [8]. Habrá que manipular con cuidado para evitar la hemorragia de los pequeños vasos de la zona. Si no se consigue de esta manera, se podría intentar mediante aspiración a través de agujero espinal entre LI y L2.

La zona de piel donde se va a realizar la punción lumbar se desinfecta con lugol-povidona al $10 \%$ y se deja secar, procediéndose a la extracción de la mayor cantidad posible de líquido.

\subsection{3.- TE}

Se recomienda el estudio de bazo, hígado, pulmón, miocardio, cerebro, riñón y glándulas suprarrenales. Se requiere solo una pequeña cantidad de muestra (una cuña) de cada uno de estos tejidos, que se introduce en un vial estéril. Se cauteriza una superficie amplia con espátula al rojo y con ayuda de instrumental estéril se toma un bloque de tejido de $1 \mathrm{~cm}^{3}$, empleando un equipo para cada muestra. 


\subsection{4.- ORINA.}

Se recoge por punción de la vejiga. Es una muestra útil para el estudio de antígenos bacterianos, especialmente ante la sospecha de $S$. pneumoniae.

\section{3.- ESTUDIO MICROBIOLÓGICO: TÉCNICAS DE LABORATORIO.}

El protocolo microbiológico ante una sospecha de infección meningocócica o de shock séptico fulminante se realiza sistemáticamente desde 200 I en el Departamento de Madrid del INTCF, al que se pueden enviar las muestras antes indicadas desde cualquier punto del país (Figura I). Este protocolo consta de las siguientes fases:

\subsection{I.- DETECCIÓN DE ANTÍGENOS BACTERIANOS.}

Investiga la presencia de las bacterias que más frecuentemente son responsables de infecciones fulminantes (meningitis y shock séptico) mediante la detección de sus antígenos en suero, LCR, exudado pleural y orina.

Se trata de unas técnicas rápidas ( $1 / 2$ hora), sensibles y que no suelen presentar falsos positivos. Su carácter es presuntivo, por lo que se deben confirmar mediante análisis moleculares y/o cultivo bacteriano. Estas técnicas son:

5.3. I. I.- Aglutinación en látex, que detecta antígenos polisacarídicos capsulares de $N$. meningitidis serogrupos $A, B, C, Y$ y WI35, S. pneumoniae, $H$. influenzae serotipo b, Streptococcus $\beta$-hemolítico del grupo B (S. agalactiae) y Escherichia coli KI2 [9]. Esta técnica se ha validado en muestras forenses y ha demostrado su utilidad para el diagnóstico de infecciones fulminantes por estos agentes. $[1,10]$. El protocolo del INTCF incluye el empleo conjunto de dos kits comerciales diferentes, lo que permite confirmar tanto los resultados positivos como los negativos. Las muestras necesarias son suero, LCR y orina.

Aunque en general esta técnica no tiene una sensibilidad muy alta, en el caso de infecciones fulminantes con evolución fatal suele existir una alta concentración de antígenos circulantes, por lo que la sensibilidad es mayor que en muestras clínicas de individuos vivos. Además, cuando las muestras forenses se hallan en buen estado de conservación, se suele obtener una adecuada correlación con la PCR [I0].

5.3. I.2.- Inmunocromatografía. Esta técnica se aplica a la detección de antígenos capsulares de $S$. pneumoniae, siendo el LCR la muestra de elección.

\subsection{I.3.- Inmunoensayo para detección de antígeno de Streptococcus pyogenes} ( $\beta$-hemolítico del grupo A).

Este método, inicialmente diseñado para los exudados faríngeos [I I ], también ha sido aplicado satisfactoriamente por los autores a la detección de infección fulminante por S. pyogenes en suero, líquido pleural y LCR.

\subsection{2.- DIAGNÓSTICO MOLECULAR.}

Consiste en la detección de genes específicos de los microorganismos patógenos con la técnica de PCR. La presencia de ADN de patógenos en muestras forenses consideradas estériles (sangre, LCR, líquido pleural...) se considera diagnóstica. Se trata de técnicas muy especíícas y sensibles, que permiten la detección de algunos microorganismos lábiles cuyo crecimiento en medios 
de cultivo a partir de muestras forenses es difíil ( $N$. meningitidis, $S$. pneumoniae etc.). Por este motivo y por su rapidez (3 horas), esta tecnología presenta grandes ventajas frente al cultivo. Se trata de técnicas no comerciales, basadas en estudios de diversos Centros de Referencia de Microbiología (Instituto Nacional de la Salud Pública de Manchester, CDC e Instituto Pasteur) [12, I3, I 4] y que han sido validadas en el INTCF para su empleo forense.

Las muestras que se pueden analizar son sangre, suero, LCR, líquido pleural y tejidos y órganos en fresco (corazón, pulmón, bazo, hígado, riñón, suprarrenales y cerebro). Excepcionalmente se podrían analizar cortes de parafina de muestras fijadas con formol mediante técnicas de PCR; sin embargo, el rendimiento de estas técnicas es mucho menor que cuando se aplican a muestras en fresco, ya que el tratamiento con formol fragmenta y altera el ADN.

En el INTCF la detección de material genético se realiza mediante ensayos de PCR a tiempo real con oligonucleótidos y sondas Taq-Man MGB diseñados para amplificar regiones específicas de cada una de las especies estudiadas. Esta técnica permite cuantificar la cantidad del producto de amplificación obtenido, correlacionándolo con unas medidas de fluorescencia que se monitorizan automáticamente, por lo que también se le denomina PCR cuantitativa. En el supuesto de meningitis bacteriana y/o shock séptico fulminante, se analizan los siguientes agentes:

I.- Investigación de N. meningitidis mediante detección del gen ctr-A, común a todas los serogrupos de esta especie.

2.- Detección de los serogrupos B, C, WI35 e Y de N. meningitidis mediante el análisis del gen siaD.

3.- Investigación de S. pneumoniae mediante detección del gen de la pneumolisina ply.

4.- Investigación de H. influenzae mediante detección del gen bex-A que codifica la exportación del polisacárido capsular.

Concretamente, aunque existen otras técnicas basadas en la PCR, consideramos que la PCR a tiempo real es la más adecuada para aplicar a muestras forenses ante el supuesto de shock séptico o meningitis meningocócica, dada la necesidad de detectar o excluir con la mayor rapidez posible la presencia de $N$. meningitidis, puesto que esta permite obtener un resultado fiable solo en unas horas desde el inicio del análisis.

\subsection{3.- CULTIVO BACTERIOLÓGICO.}

En microbiología clínica el cultivo bacteriano es la técnica de referencia o "gold standard"; no obstante, en microbiología forense no siempre se ha considerado como útil, dado el elevado grado de contaminación de las muestras, que se suele deber a la falta de asepsia durante la toma. Otra razón de su menor utilidad es que aquellos microorganismos más lábiles pueden no crecer en los medios de aislamiento, ocasionando falsos negativos. No obstante, un resultado positivo en el aislamiento de bacterias patógenas no ofrece dudas acerca de su interpretación, aportando siempre datos claves para establecer la etiología de la causa de muerte [15]. Por ello, consideramos que en microbiología forense no se debe prescindir del cultivo, sino que este debe complementarse con otras técnicas como las antigénicas y moleculares [16]. 
Ante la sospecha de una meningitis bacteriana o un shock séptico fulminante, aunque las técnicas moleculares permiten la detección específica, rápida y sensible de los patógenos investigados, es conveniente realizar también un cultivo para aislar la bacteria responsable de la muerte. Este tendría dos objetivos fundamentales: confirmar los resultados moleculares y antigénicos, y caracterizar la cepa de la bacteria aislada con fines epidemiológicos. Estos resultados se suelen obtener entre 24 y 72 horas.

El cultivo bacteriológico se puede efectuar en sangre (hemocultivos), LCR, líquido pleural y tejidos y órganos en fresco, pudiendo realizarse una tinción de Gram en el LCR como técnica de screening previo [9].

\section{6.- RECOMENDACIONES SANITARIAS:}

\section{I.- INFORMACIÓN A LAS AUTORIDADES SANITARIAS COMPETENTES.}

Las meningitis bacterianas son enfermedades de declaración obligatoria. Ante su sospecha se debe realizar una declaración urgente a la Unidad de Vigilancia Epidemiológica de la Dirección Territorial de Sanidad (Consejería de Salud). En el caso de infección meningocócica, una vez conocido el serogrupo se deberá comunicar con la mayor rapidez posible para valorar la necesidad de vacunación de los contactos no vacunados. Tras aislar la cepa, esta deberá ser analizada para su tipado.

\section{2.- MANEJO DE LOS CONTACTOS.}

La recomendación de quimioprofilaxis a los contactos estrechos en un caso de enfermedad meningocócica deberá realizarse tan pronto como sea posible, idealmente en las primeras 24 horas después del diagnóstico. Si por alguna razón no se hubiera podido detectar antes, incluso se podría iniciar hasta un plazo de 10 días después de los síntomas; no obstante, su eficacia es dudosa pasado dicho tiempo. Para la instauración temprana de las medidas preventivas es importante un diagnóstico precoz. En los casos debidos a serogrupos para los que se dispone de vacuna, se recomienda su administración para evitar los casos secundarios tardíos, ya que su efecto se produce tras 10- I 5 días de su administración.

\section{3.- RECOMENDACIONES PARA EL PERSONAL SANITARIO.}

Aquel personal sanitario que ha realizado maniobras de resucitación boca a boca, se considera con riesgo de enfermedad alto y se recomienda quimioprofilaxis. Por el contrario, para el personal sanitario sin exposición directa a las secreciones orales del paciente la quimioprofilaxis no es recomendada al considerarse de riesgo bajo.

En el caso del personal sanitario de autopsias no existen unas instrucciones claras sobre profilaxis. Con relación a la vacuna conjugada frente al meningococo C, esta es muy eficaz, de larga duración (teóricamente y por los estudios realizados hasta el momento, confiere inmunidad para toda la vida, aunque hay que señalar que dichos estudios no tienen más de 5 años) y poco reactógena, por lo que podría estar recomendada al personal sanitario de autopsias, si bien el número de casos detectados es bajo. Por este motivo, no se han definido líneas de actuación al respecto. Otra posibilidad, es la vacunación o profilaxis de este personal una vez que se ha detectado el caso y se ha identificado el serogrupo responsable en el laboratorio. Por otro lado, debido al potencial riesgo de contagio durante la autopsia, se recomiendan medidas de protección durante esta y durante el tratamiento posterior de las muestras en laboratorio, como son el empleo de guantes, mascarilla, gafas, así como la manipulación de las muestras en campana de seguridad biológica de tipo II y su centrifugación en tubos cerrados empleando centrífugas con tapa de seguridad. 


\section{AGRADECIMIENTOS:}

Este artículo no sería posible sin la inestimable colaboración de Ma Paz Suárez-Mier y Beatriz Aguilera Tapia, patólogas del Servicio de Histopatología del Departamento de Madrid del INTCF, cuya gran experiencia en los estudios de muerte súbita ha sido de gran valía para los autores.

También queremos resaltar la inapreciable ayuda prestada por todos los profesionales que participan en la aplicación a la rutina diaria del protocolo de trabajo aquí presentado: técnicos especialistas de laboratorio del Servicio de Biología del Departamento de Madrid del INTCF y del Servicio de Patología de Bizkaia (en particular la de Ma José Burguete García y Esther Espinosa de los Monteros en Madrid y Aida Larrañaga en Bizkaia), así como los auxiliares de autopsia de Bizkaia (Jon Txomin Martín, Kontxi Moreno; Ricardo Ballesteros, Itziar Turienzo; Juan Ojanguren, Diego Burón y Jose Ignacio Raño).

\section{BIBLIOGRAFÍA:}

I.- Challener RC, Morrissey AM, Jacobs MR: Postmortem diagnosis of meningococcemia by detection of capsular polysaccharides. J. Forensic Sci. 1988; 33: 336-346.

2.- McGee ZA, Baringer JR. Acute meningitis. En: Mandell GL, Douglas RG, Bennett JE. Principles and Practice of Infectious Diseases, 3rd edition, Churchill Livingstone, New York, 1990. pp. 74I-755.

3.- Boletín epidemiológico de la Comunidad de Madrid. Enfermedad meningocócica. Informe de la temporada 2002-03. Vol 10, n⿳0 3, marzo 2004.

4.- Vázquez JA: Enfermedad meningocócica y vacunación: un nuevo escenario. Vacunas 2001; 2, Supl. 2:I-4.

5.- Cano Portero R, García Delgado C, de Mateo Ontanon S: Meningococcal disease. The situation in Spain in the 1998-1999 period. Rev. Esp. Salud Publica. 2000; 74: 369-375.

6.- Castell C, García Calabuig MA, Tobalina MC, Robertson M: Profilaxis de la infección meningocócica. Departamento de Sanidad de la Comunidad Autónoma del País Vasco. Vitoria-Gasteiz, 2004.

7.- Chaudhuri AK, Hartley RB, Maddocks AC: WaterhouseFriderichsen syndrome caused by a DF-2 bacterium in a splenectomised patient. J. Clin. Pathol. 1981; 34: 172-173.

8.- Ludwig J, Handbook of Autopsy Practice, $3^{\circ}$ ed. Human Press. New Jersey, 2002.

10.- Fernández-Rodríguez A, Vázquez JA, Suárez-Mier MP, Aguilera B, Ballesteros S, de la Fuente L, Vallejo G, Sancho M: Latex agglutination for bacterial antigens and meningococcus PCR: two useful tools in legal sudden deaths. Forensic Sci. Int. 2005; I47: 13-20.

II.- Betriú C, Fernández-Rodríguez A: Evaluation of four methods for the detection of streptococcal group A antigen directly from throat swabs. Microbiología SEM. 1988; 4: 177-179.

I2.- Taha MK: Simultaneous approach for nonculture PCR-based identification and serogroup prediction of Neisseria meningitidis. J. Clin. Microbiol. 2000;38: 855-857.

13.- Corless CE, Guiver M, Borrow R, Edwards-Jones V, Fox AJ, Kaczmarski EB: Simultaneous detection of Neisseria meningitidis, Haemophilus influenzae, and Streptococcus pneumoniae in suspected cases of meningitis and septicemia using real-time PCR. J. Clin. Microbiol. 200I; 39: I553-I558.

14.- Mothershed EA, Sacchi CT, Whitney AM, Barnett GA, Ajello GW, Schmink S, Mayer LW, Phelan M, Taylor RH, Bernhardt SA, Rosenstein NE, Popovic T: Use of Real-Time PCR to resolve slide agglutination discrepancies in serogroup identification of Neisseria meningitidis. J. Clin. Microbiol. 2004; 42:320-328.

I5.- Roberts F): Procurement, interpretation, and value of postmortem cultures. Eur. J. Clin. Microbiol. Infect. Dis. 1998; 17: 821-827.

9.- Apicella MA. Neisseria meningitidis. En: Mandell GL, Douglas RG, Bennett JE. Principles and Practice of Infectious Diseases, 3rd edition, Churchill Livingstone, New York, 1990. pp. 1600-1613.

16.- Gerber JE, Johnson JE, Scott MA, Madhusudhan KT: Fatal meningitis and encephalitis due to Bartonella henselae bacteria. J. For. Sci. 2002; 47: 640-644. 